\section{CARBUTAMIDE IN DIABETES}

REPORT OF A LONG-TERM TRIAL, WITH SPECIAL REFERENCE TO LATE FAILURES

BY

ANTTI MARKKANEN, M.D. MARTTI OKA, M.D.

AND

PENTTI PELTOLA, M.D.

From the Medical Department, Kivelä Hospital, Helsinki

Since the introduction of oral treatment of diabetes in 1955 (Bertram, Bendfeldt, and Otto, 1955 ; Franke and Fuchs, 1955), research work in this field has rapidly increased and over 1,000 papers on the subject have been published. Nevertheless, the mechanism of action of the compounds used is still a subject of controversy. The reported results of long-term treatment have shown great variations, probably because of lack of uniformity in the indications for oral treatment and in the criteria used to assess benefit. In addition, the period of treatment has usually been relatively short, which makes the evaluation of late results difficult.

Some early reports drew attention to failure of treatment after prolonged administration (Heinsen and Hagen, 1956 ; Engelhard, 1956 ; Brechman, 1957 ; Otto, 1957 ; Mohnike et al., 1957; Pfeiffer et al., 1957; Dotevall, 1958). These so-called late failures have often been attributed to neglect of the diet, unsuitability of the patient for oral treatment, infections (Bertram, 1958), or similar causes. Other authors have referred to the possibility of the beta cells failing to function after prolonged oral therapy (Pfeiffer, 1957) and lack of response due to the development of tachyphylaxis against the drug (Heinsen and Hagen, 1956).

In the present investigation, special attention has been paid to the results of long-term therapy. Oral antidiabetic therapy was instituted in this hospital in the autumn of 1955. Thus at the time this report was written some of our patients had received this treatment for over three years.

\section{Material and Methods}

The series consisted of 270 patients whose treatment with carbutamide (N-butyl-N-sulphanilylurea, "BZ55") was begun during the period November, 1955 , to January, 1957-that is, $28-42$ months before the end of the follow-up time. In conformity with the generally approved principles, oral treatment was instituted in middle-aged or elderly patients in whom diet alone did not adequately control the diabetes and in insulin-treated patients whose insulin requirements were not high.

In most cases the treatment was begun at the hospital, and the patient was instructed about the necessity of maintaining a strict diet. The dosage was $2.5 \mathrm{~g}$. On the first day, $2 \mathrm{~g}$. On the second day, $1.5 \mathrm{~g}$. on the third day, and thereafter according to the individual needs of the patient. If necessary it was increased later up to 2-2.5 g. a day. After discharge from the hospital all the patients were examined in the out-patient department at intervals of one to three months.
The criteria used in assessing the results of treatment were improvement in the patient's general condition, gain in weight, disappearance of thirst and polyuria, and nonappearance of complications of diabetes. The laboratory tests carried out were estimations of the blood-sugar, urine-sugar, and urine-protein values, and tests for ketosis. Since most of the patients were regularly employed outside their homes and the collection of 24hour urine specimens was therefore not possible during working hours, the determination of sugar in urine had to be made from as much of the 24-hour specimen as was available. This method does not give a fully correct picture of the urinary excretion of sugar during 24 hours, but together with the blood-sugar determination it may be regarded as a satisfactory indication of the effectiveness of control of the disease.

Differential blood counts and liver-function tests were at first carried out monthly, but later at longer intervals.

The treatment was regarded as successful if, in addition to improvement in the clinical signs, the fasting blood-sugar in the morning was below $200 \mathrm{mg} . / 100 \mathrm{ml}$. (Hagedorn) and the sugar content of the urine below $1 \%$, corresponding to an average 24-hour excretion of about $10-15 \mathrm{~g}$. of sugar. Transient increases above these values were not taken into consideration. If the fasting blood-sugar value persisted at over $200 \mathrm{mg}$./100 $\mathrm{ml}$. or the urine sugar at over $1 \%$ despite increase of the carbutamide dosage up to $2-2.5 \mathrm{~g}$. a day, treatment was regarded as having failed.

Patients whose treatment was successful during the first month, and later proved a failure, have been classified under "late failures." To clarify the part played by possible dietetic errors, the late failures were usually admitted to hospital for two to three weeks for observation, and carbutamide was continued in the same dose as before.

\section{Results in Patients Previously under Dietetic Treatment Only}

Of the 262 diabetic patients in this series, 148 had been treated by dietetic restrictions only. Primary failure during the first month occurred in 27 of these cases (18\% of the group). Among the cases that at first were successful, there were 46 late failures (37\% of the originally. successful cases) (Table I). From 12 to $27 \%$ of the patients treated became "late failures" in each yearly period of observation. The number of late failures was relatively largest among the younger patients, being $80 \%$ among those who were 30-39 years of age at the onset of diabetes and $60 \%$ in those who were 40-49 years. Late failures were fewer among those who were older when the disease began, being

TABle I.-Distribution of Late Failures by Age at Onset of Diabetes and Duration of Oral Treatment. Patients Previously Treated by Dietetic Means Only. Failures/ Patients During Corresponding Period

\begin{tabular}{|c|c|c|c|c|c|c|}
\hline \multirow{2}{*}{$\frac{\begin{array}{c}\text { Age at Onset } \\
\text { of Diabetes }\end{array}}{\text { Years }}$} & \multicolumn{4}{|c|}{$\begin{array}{c}\text { Duration in Years of } \\
\text { Oral Treatment }\end{array}$} & \multicolumn{2}{|c|}{$\begin{array}{c}\text { Late } \\
\text { Failures }\end{array}$} \\
\hline & $<1$ & $1-$ & $2-$ & $3-4$ & Total No. & $\%$ \\
\hline $\begin{array}{l}30-39 \\
40-49 \\
50-59 \\
60-69 \\
70-79 \\
80-\end{array}$ & $\begin{array}{l}2 / 5 \\
3 / 10 \\
5 / 40 \\
9 / 49 \\
1 / 15 \\
0 / 2\end{array}$ & $\begin{array}{l:l}2 & 3 \\
2 & 6 \\
4 & 22 \\
6 & 35 \\
2 & 11 \\
0 & 1\end{array}$ & $\begin{array}{l}0 / 1 \\
1 / 4 \\
1 / 12 \\
2 / 27 \\
2 / 7 \\
0 \\
0\end{array}$ & $\begin{array}{l:l}0 & 0 \\
0 & 1 \\
2 & 7 \\
2 & 7 \\
0 & 0 \\
0 & 0\end{array}$ & $\begin{array}{c}4 / 5 \\
6 / 10 \\
12 / 40 \\
19 / 49 \\
5 / 15 \\
0 / 2\end{array}$ & $\begin{array}{r}80 \\
60 \\
30 \\
39 \\
33 \\
0\end{array}$ \\
\hline $\begin{array}{l}\text { Total ... } \\
\text { Percentage }\end{array}$ & $20 / 121$ & $\begin{array}{c}16 / 78 \\
21\end{array}$ & $\begin{array}{c}6552 \\
12\end{array}$ & $\begin{array}{l}4 / 15 \\
27\end{array}$ & $46 / 121$ & 37 \\
\hline
\end{tabular}


$34 \%$ in those over 50 years of age at the time of onset of diabetes. But even in this group late failures occurred, even after successful treatment for one to two years with normal blood-sugar values (under $120 \mathrm{mg} . / 100 \mathrm{ml}$.) and sugar-free urine.

During the period of observation the number of patients under treatment declined somewhat, because of deaths or transfer elsewhere for treatment.

A definite correlation could not be observed between the number of late failures and the duration of the disease before the beginning of oral therapy (Table II).

TABLE II.-Distribution of Late Failures by Duration of Diabetes and Oral Treatment. Patients Previously Treated by Dietetic Means Only. Failures/Patients During Corresponding - Period

\begin{tabular}{l|c|c|c|c|c|c|c}
\hline \multirow{2}{*}{$\begin{array}{c}\text { Duration } \\
\text { of Diabetes }\end{array}$} & \multicolumn{2}{|c|}{ Duration in Years of Oral Treatment } & \multicolumn{2}{|c}{ Late Failures } \\
\cline { 2 - 7 } & $<1$ & $1-$ & $2-$ & $3-4$ & Total No. & $\%$ \\
\hline Under 1 year & $9 / 57$ & $5 / 41$ & $1 / 26$ & $2 / 6$ & $17 / 57$ & 30 \\
$1-4$ years & $8 / 39$ & $7 / 20$ & $3 / 15$ & $1 / 5$ & $19 / 39$ & 49 \\
5-10 & $3 / 20$ & $3 / 12$ & $1 / 9$ & $1 / 4$ & $8 / 20$ & 40 \\
Over 10 yrs. & $0 / 5$ & $1 / 5$ & $1 / 2$ & $0 / 0$ & $2 / 5$ & 40 \\
\hline
\end{tabular}

In cases with a history of diabetes of less than one year's duration the late-failure rate was $30 \%$, in those with a history of one to four years $49 \%$, and in those with a longer history $40 \%$.

\section{Results in Patients Previously Treated with Insulin}

The number of cases treated previously with insulin was 114. Primary failure during the first month of carbutamide therapy occurred in $56 \%$. There were also more late failures $(50 \%)$ in this group of patients than in the group which had previously had diabetic treatment only. Late failure was not clearly related to the age at onset of diabetes in the patients previously treated with insulin (Table III). It is true that both

TABLB III.-Distribution of Late Failures by Age at Onset of Diabetes and Duration of Oral Treatment. Patients Treated Earlier with Insulin. Failures/Patients During Corresponding Period

\begin{tabular}{c|c|c|c|c|c|c}
\hline \multirow{2}{*}{$\begin{array}{c}\text { Age at } \\
\text { Onset of } \\
\text { Diabetes }\end{array}$} & \multicolumn{2}{|c|}{ Duration in Years of Oral Treatment } & \multicolumn{2}{c}{ Late Failures } \\
\cline { 2 - 6 } \cline { 5 - 6 } & $<1$ & $1-$ & $2-$ & $3-4$ & Total No. & $\%$ \\
\hline $30-39$ years & $2 / 2$ & $0 / 0$ & $0 / 0$ & $0 / 0$ & $2 / 2$ & 100 \\
$40-49$ & $2 / 6$ & $1 / 3$ & $0 / 1$ & $0 / 1$ & $3 / 6$ & 50 \\
$50-59$ & $4 / 14$ & $1 / 6$ & $1 / 4$ & $2 / 2$ & $8 / 14$ & 57 \\
$60-69$ & $3 / 15$ & $1 / 10$ & $1 / 8$ & $0 / 4$ & $5 / 15$ & 33 \\
$70-79$ & $6 / 13$ & $1 / 5$ & $0 / 2$ & $0 / 1$ & $7 / 13$ & 54 \\
\hline $\begin{array}{l}\text { Total } \\
\text { Percentage }\end{array}$ & $17 / 50$ & $4 / 24$ & $2 / 15$ & $2 / 8$ & $25 / 50$ & 50 \\
\hline
\end{tabular}

of those who were under 40 years of age and $50 \%$ of those who were $40-49$ at the time of onset were failures ; but the number of patients in these subgroups was very small and therefore assessment in terms of percentages has little significance. Of those aged 50-59 at onset $57 \%$ were late failures and of those aged 70-79 at onset $54 \%$ were late failures. The proportion of late failures occurring during each yearly period of observation varied from 13 to $34 \%$.

The influence of the duration of the disease on the late-failure rate was apparent in this group (Table IV). In those with diabetes for less than one year, the latefailure rate was $29 \%$ among the originally successful cases. The rate was much higher (50-67\%) among those with a longer history of the disease.
TABLE IV. - Distribution of Late Failures by Duration of Diabetes and Oral Treatment. Patients Treated Earlier by Insulin. Failures/Patients During Corresponding Period

\begin{tabular}{l|c|c|c|c|c|c}
\hline \multirow{2}{*}{$\begin{array}{c}\text { Duration } \\
\text { of Diabetes }\end{array}$} & \multicolumn{2}{|c|}{ Duration in Years of Oral Treatment } & \multicolumn{2}{c}{ Late Failures } \\
\cline { 2 - 7 } & $<1$ & $1-$ & $2-$ & $3-4$ & Total No. & $\%$ \\
\hline Under 1 year & $2 / 7$ & $0 / 4$ & $0 / 3$ & $0 / 0$ & $2 / 7$ & 29 \\
$1-4$ years & $5 / 19$ & $3 / 10$ & $1 / 7$ & $1 / 6$ & $10 / 19$ & 53 \\
$5-10$ & $6 / 18$ & $1 / 10$ & $1 / 5$ & $1 / 2$ & $9 / 18$ & 50 \\
Over 10 yrs. & $4 / 6$ & $0 / 0$ & $0 / 0$ & $0 / 0$ & $4 / 6$ & 67 \\
\hline
\end{tabular}

The average insulin requirement of the patients who became late failures remained approximately the same as before the oral treatment was begun, being approximately 42 units $/ 24$ hours before oral treatment and approximately 43 units after its discontinuation. The required dosage of insulin was greater after the treatment in four cases but was less in three cases. The average pre-treatment dose of insulin in cases of late failure was higher (42 units) than that of the patients whose oral treatment continued to be successful ( 28 units).

\section{Observations on Late Failures}

The sex distribution was the same among the late failures and in the group whose disease remained successfully controlled by carbutamide. The difference in the mean blood-pressure values in these two groups was not statistically significant.

Ketosis appeared to be present before the commencement of oral therapy in a larger proportion of the cases that were failures. However, in 12 of the remaining successful cases there also had been ketosis before oral therapy began.

Albuminuria developed during oral therapy in five successful cases and disappeared in one case.

A diagnosis of peripheral neuritis was made in one patient during oral therapy. The onset or increase of retinopathy was not observed during successful treatment in the 35 cases whose fundi were examined before and during treatment.

Late failure due to dietetic error occurred in one case only. This patient's condition improved with strict dieting during his stay in hospital, enabling oral treatment to be continued. In the other cases of failure a controlled diabetic diet in the hospital could not restore the blood-sugar to a level that would have permitted continuation of oral therapy. Increasing the dosage of carbutamide as the blood sugar rose merely postponed the time of ultimate failure by one to six months.

The insulin requirements of the patients previously treated by a diabetic diet were in the range of $20-40$ units/24 hours after late failure. In 10 cases of late failure a new attempt at oral treatment of diabetes was made after 1 to 12 months' insulin treatment: in eight of these it was possible to keep up the treatment with success, in some for as long as four months, but an estimation of the permanence of the results is not yet possible.

Dermatitis occurred as a side-effect of treatment in 14 patients $(5.2 \%$ of the total series). In two patients it developed immediately after the first doses, in nine during the first months, and in three at a later stage. Treatment had to be discontinued in seven cases, but in the others its continuance was possible after a short interval. No changes were observed in the differential 
blood counts and liver-function tests during the three years of oral treatment of diabetes.

\section{Discussion}

The percentage of late failures with oral antidiabetic therapy ranges from 4 to 20 in different reports (Brechmann, 1957 ; Mohnike et al., 1957 ; Pfeiffer et al., 1957 ; Dotevall, 1958). Evidently the principal reasons for this are differences in the indications for oral therapy and in the criteria of successful treatment. The principle that oral antidiabetic therapy should be instituted only when control of the disease by diet is inadequate is probably generally acceptable. The requirement that the fasting blood-sugar value should be maintained in the range of $110-130 \mathrm{mg} . / 100 \mathrm{ml}$. (Pote et al., 1958) means that there will be more early failures than if a critical value of $200 \mathrm{mg} . / 100 \mathrm{ml}$. is used, as was done in the present investigation.

As in many earlier investigations, we also found that the treatment was more successful when (1) the onset of the disease was late in life (diet group), (2) the disease had been treated earlier by dietary regimen alone, (3) the disease had been of short duration before oral therapy was begun (insulin group), and (4) the insulin requirement had been small. The proportion of late failures was smaller in these groups, but it increased as the period of oral treatment lengthened. Since these groups generally comprise mild cases of diabetes, it would seem that oral diabetic treatment, even in mild cases, is merely able to postpone the use of insulin. But the milder the diabetes the longer this postponement will generally be.

In studying the possible causes of late failure we were able to ascribe the failure to dietetic negligence in one case only. Infection was not found to be more than temporarily an aggravating factor in any of the cases. Some of the late failures were due to the fact that our series was an unselected one and included some patients who were less suitable than others for oral treatmentfor example, cases with an early onset. However, even among these there were cases still being successfully controlled after nearly three years of treatment. On the other hand, the occurrence of late failures in the groups which are generally regarded as well suited for oral therapy points to the probability that the drug, even in these cases-and possibly in all cases-gradually loses its effect during long-term administration. The failure of beta cells (Pfeiffer, 1957) can hardly be regarded as the cause of late failure of oral therapy, since the requirement of exogenous insulin did not increase after unsuccessful treatment. Also, after a short period of insulin treatment in late failures the reinstitution of oral therapy was sometimes successful. Further evidence supporting this conclusion is provided by animal experiments, in which very large doses of antidiabetic drugs (Bänder, 1957) given during nine months produced no changes in the pancreas histologically or in its insulin output.

Despite the fact that the benefit from oral treatment may be only temporary, this therapy is of considerable value in the treatment of mild diabetes. In the selection of patients for oral treatment the course which the disease has run in any particular patient does not always provide a good basis for estimating long-term results, since some of our successful cases had developed diabetes at an early age. A history of ketosis, which in the early days of oral therapy was regarded as a contraindication, does not always point to a late failure in the light of our results.

According to the present investigation the toxic effects of carbutamide were only slight. Since a number of reports (Bertram, 1958) provide evidence that it is more effective than, for example, tolbutamide in the treatment of diabetes consideration should be given to the use of carbutamide in suitable cases.

\section{Summary}

This investigation was carried out to assess the value of prolonged treatment with an orally administered antidiabetic drug, carbutamide. The series comprised 262 diabetics who had started on oral treatment 28 to 42 months earlier. The treatment was unsuccessful during the first month in $18 \%$ of a group of 148 patients with diabetes previously treated by diet alone. Later in the course of the treatment there were failures in $37 \%$ of the remaining cases in this group. Among these late failures were patients who were considered most suitable for this treatment-that is, those whose disease had developed in later life and was of short duration.

In the group of 114 patients previously treated with insulin there were primary failures during the first month in $56 \%$ and late failures in $50 \%$ of the patients who at first reacted successfully. The average insulin requirement did not increase after the failure of oral therapy.

No increase was observed in the complications of diabetes among those whose disease was successfully controlled by carbutamide. The untoward effects of the drug were slight even during long-term administration.

The occurrence of failures during long-term oral treatment, even among the patients apparently most suitable for this therapy, may point to a gradual disappearance of response to treatment, possibly due to some compensatory mechanism in the organism. In several cases of late failure of oral treatment, carbutamide regained its effectiveness, at least for a time, after the patient had been treated with insulin.

REFERENCES

Bänder, A. (1957). In Aktuelle Diabetesfragen: Symposion in Hamburg, edited by F. Bertram and J. Kuntzé, p. 16. Thieme, Stuttgart.

Bertram, F. (1958). Third Congress of the International Diabetes Federation, Düsseldorf. Scheffler, Lübeck.

Bendfeldt, E., and Otto, H. (1955). Disch. med. Wschr., 80,1455 .

Brechmann, K. (1957). Aktuelle Diabetesfragen: Symposion in Hamburg, edited by F. Bertram and J. Kuntze, p. 35 . Thieme, Stuttgart.

Dotevall, G. (1958). Acta med. scand., 161, 251.

Engelhard, H. (1956). Medizinische, p. 1639.

Franke, H., and Fuchs, J. (1955). Dtsch. med. Wschr., 89, 1449. Heinsen, H. A., and Hagen, H. (1956). Med. Klin., 51, 1217.

Mohnike, G., Ulrich, H., and Jutzi, E. (1957). Dtsch. med. Wschr., 82, 1524.

Otto, H. (1957). Aktuelle Diabetesfragen: Symposion in Hamburg. Thieme, Stuttgart.

Pfeiffer, E. F. (1957). J. Endocr., 15, xlviii. Schöffling, K., Steigerwald, H., Treser, G., and Otto, M. (1957). Dtsch. med. Wschr., 82, 1528.

Pote, W. W. H., Anderson; A., and Cochran, B. (1958). Third Congress of the International Diabetes Federation, Düsseldorf. Scheffler, Lübeck. 